\title{
Medical Image of the Week: Moyamoya Disease
}

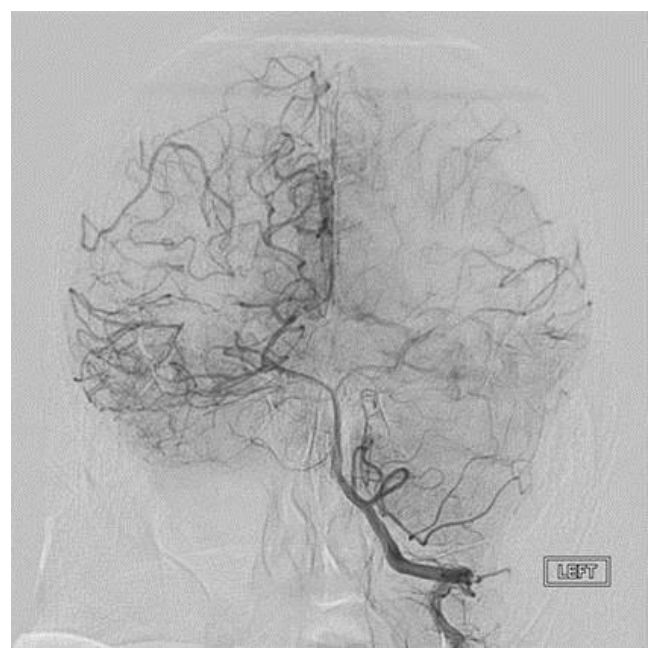

Figure 1. Cerebral angiogram of the brain demonstrating bilateral high-grade stenosis of the anterior and middle cerebral arteries, worse on the left.

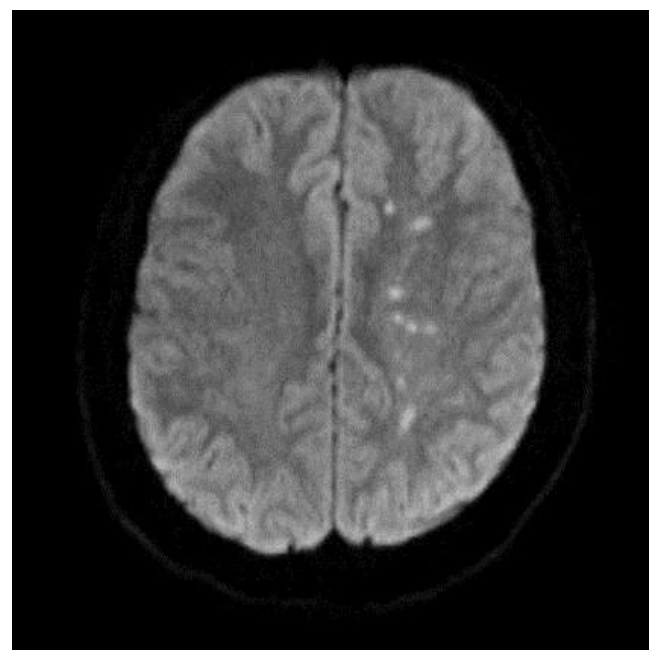

Figure 2. Magnetic resonance imaging showing multiple punctate infarcts in the frontal and parietal lobes on the left side.

A 52-year-old, right-handed, Caucasian woman with a history of hypertension and morbid obesity presented with acute onset of word-finding difficulty and slurred speech. Her medical and family history was negative for cerebral vascular event, coronary artery disease or smoking. Computed tomography of the patient's brain showed narrow caliber middle cerebral artery vasculature bilaterally. This abnormal finding prompted further investigation with cerebral angiogram. The angiogram showed bilateral high-grade stenosis of the anterior 
and middle cerebral arteries, worse on the left (Figure 1). Magnetic resonance imaging revealed multiple left sided punctate infarcts in the frontal and parietal lobes (Figure 2). Diagnosis of ischemic stroke secondary to moyamoya disease was established. This patient was not a candidate for fibrinolytic therapy since it had been more than 4 hours from initial presentation. She was treated with aspirin, clopidogrel, and atorvastatin for secondary prevention of ischemic stroke. Two months after her discharge date, the patient had a middle cerebral artery to superior temporal artery bypass on the left side, followed by a middle cerebral artery to superior temporal artery bypass on the right two months after initial bypass. Patient progressed to an uneventful recovery. Discharge planning included the continuation of aspirin, clopidogrel, and atorvastatin indefinitely.

Moyamoya disease (MMD) is an uncommon vasculopathy of unknown origin associated with diverse risk factors (1). It was first discovered in a Japanese population, and reported more commonly in this sub-population. However, numerous cases were reported across the globe (2). Moyamoya disease associated with other systemic condition such as neurofibromatosis type 1 , trisomy 21 , thyroid cranial irradiation or thyroid disease is termed moyamoya syndrome (MMS) $(1,2)$. Moyamoya syndrome is a cerebrovasculopathy originating from collateral flow that develops secondary to occlusion of the internal carotid artery and the proximal afferent vessels at the circle of Willis (3). MMS can have abrupt or insidious onset and may progress to diversifying cerebral ischemic stroke or to intracranial hemorrhage, which is a worse prognosis and the primary cause of death in patients with MMD (4). It has been shown that ischemic stroke associated with MDD or MMS usually occurs when compensatory collateral vessels are unable to supply sufficient blood to the brain after occlusion or stenosis of the internal carotid arteries or its tributary vessels $(5,6)$. On the other hand, intracranial hemorrhage occurs secondary to the rupture of abnormal moyamoya vessels $(7,8)$.

It is imperative to differentiate between non-hemorrhagic and hemorrhagic moyamoya. Neuroimaging is the preferred method of diagnosis after high clinical suspicion of MMD or MMS. Intracranial hemorrhage and cerebral infarction can be diagnosed with computed tomography and magnetic resonance imaging/ cerebral angiogram, respectively $(8,9)$. Recent use of magnetic resonance perfusion imaging has been shown to be crucial in diagnostics and medicalsurgical decision making. There is no common consensus when it comes to treatment of moyamoya at this time. Initial management is symptomatic with anticoagulants, antiplatelet and corticosteroids (10). Treatment options may also include direct or indirect surgical revascularization as optimal therapy $(11,12)$.

Stella Pak MD, Kokou Adompreh-Fia MD, Damian Valencia MD, Adam Fershko MD, and Jody Short DO.

Department of Medicine

Kettering Medical Center

Kettering, OH USA 


\section{References}

1. Phi JH, Wang KC, Lee JY, Kim SK. Moyamoya Syndrome: A window of moyamoya disease. J Korean Neurosurg Soc. 2015 Jun;57(6):408-14. [CrossRef] [PubMed]

2. Suzuki J, Takaku A. Cerebrovascular "moyamoya" disease. Disease showing abnormal net-like vessels in base of brain. Arch Neurol. 1969 Mar;20(3):28899. [CrossRef] [PubMed]

3. Yamamoto, S, Koh M, Kashiwazaki D, Akioka N, Kuwayama N, Noguchi K, Kuroda S. Is Quasi-moyamoya disease a uniform disease entity? A threedimensional constructive interference in steady state imaging study. J Stroke Cerebrovasc Dis. 2016 Jun;25(6):1509-16. [CrossRef] [PubMed]

4. Baba, T., Houkin, K. Kuroda. Novel epidemiological features of moyamoya disease. J Neurol Neurosurg Psychiatry. 2008 Aug;79(8):900-4. [CrossRef] [PubMed]

5. Miyamoto S, Kikuchi H, Karasawa J, Nagata I, Ihara I, Yamagata S. Study of the posterior circulation in moyamoya disease. Part 2: Visual disturbances and surgical treatment. J Neurosurg. 1986 Oct;65(4):454-60. [CrossRef] [PubMed]

6. Kuroda S, Ishikawa T, Houkin K, Iwasaki Y. Clinical significance of posterior cerebral artery stenosis/occlusion in moyamoya disease. No Shinkei Geka. 2002 Dec;30(12):1295-300. [PubMed]

7. Kang K, Lu J, Zhang D, Li Y, Wang D, Liu P, Li B, Ju Y, Zhao X. Difference in cerebral circulation time between subtypes of moyamoya disease and moyamoya syndrome. Sci Rep. 2017;7(1):2587. [CrossRef] [PubMed]

8. Lui, P, Han C, Li DS, Lv XL, Li YX, Duan L. Hemorrhagic moyamoya disease in children: Clinical, angiographic features, and long-term surgical outcome. Stroke. 2016 Jan;47(1):240-3. [CrossRef] [PubMed]

9. Kellner CP, McDowell MM, Phan MQ, Connolly ES, Lavine SD, Meyers PM, Sahlein D, Solomon RA, Feldstein NA, Anderson RC. Number and location of draining veins in pediatric arteriovenous malformations: association with hemorrhage. J Neurosurg Pediatr. 2014 Nov;14(5):538-45. [CrossRef] [PubMed]

10. Whitaker J. Management of moyamoya syndrome [comment]. Arch Neurol. 2001;58:132. [CrossRef] [PubMed]

11. Golby AJ, Marks MP, Thompson RC, Steinberg GK. Direct and combined revascularization in pediatric moyamoya disease. Neurosurg. 1999;45:50-8. [PubMed]

12. Mizoi K, Kayama T, Yoshimoto T, Nagamine Y. Indirect revascularization for moyamoya disease: is there a beneficial effect for adult patients? Surg Neurol. 1996;45:541-8. [CrossRef] [PubMed] 